Wilfrid Laurier University

Scholars Commons @ Laurier

\title{
The Motivational Quality of Global Attributions in Hypothetical and Experienced Situations of Gender Discrimination
}

Mindi D. Foster

Wilfrid Laurier University, mfoster@wlu.ca

Follow this and additional works at: https://scholars.wlu.ca/psyc_faculty

Part of the Psychiatry and Psychology Commons, and the Social Psychology Commons

\section{Recommended Citation}

Foster, Mindi D., "The Motivational Quality of Global Attributions in Hypothetical and Experienced Situations of Gender Discrimination" (2001). Psychology Faculty Publications. 38.

https://scholars.wlu.ca/psyc_faculty/38

This Article is brought to you for free and open access by the Psychology at Scholars Commons @ Laurier. It has been accepted for inclusion in Psychology Faculty Publications by an authorized administrator of Scholars Commons@Laurier. For more information, please contact scholarscommons@wlu.ca. 
Running head: Global attributions for discrimination

The Motivational Quality of Global Attributions in Hypothetical and

Experienced Situations of Gender Discrimination

Mindi D. Foster

University of North Dakota

Comments by Kimberly Matheson, Deborah Mahlstedt and anonymous reviewers on previous drafts of this manuscript are greatly appreciated. Correspondence should be addressed to Mindi D. Foster, now at the Department of Psychology, West Chester University, West Chester, PA. 19383 Phone: (610) 436 3153. Fax: (610) 436 2846. Email: mfoster@wcupa.edu

\begin{abstract}
Traditionally, global attributions have been thought to reduce instrumental behavior aimed at resolving negative events. However, the present research shows global attributions for gender discrimination are related to taking action against unfair treatment. In Study 1, women $(\underline{N}=157)$ completed a questionnaire assessing attributions for hypothetical scenarios of discrimination and collective responses to discrimination. In Study 2, women $(\underline{N}=79)$ were placed into a laboratory situation of discrimination and asked to indicate their attributions for and responses to their unfair treatment. In both studies, hierarchical regression analyses showed that global attributions were related to both individual and collective responses to their discrimination. Implications for examining attributions in an intergroup context were discussed.
\end{abstract}

The Motivational Quality of Global Attributions in Hypothetical and Experienced Situations of Gender Discrimination

If something bad happens to you (e.g., getting sick, being in an accident), and you believe, "It must be me! Nothing ever changes. It's everywhere!", an understandable reaction might be, “I give up --- I can't change anything, I might as well accept it." Certainly, according to learned helplessness theories (Abramson, Metalsky \& Alloy, 1989; Abramson, Seligman \& Teasdale, 1978; Seligman, 1975), 
"giving up" or helplessness behavior is most likely when people make internal, stable, and global attributions for uncontrollable, negative events. These attributions reflect the belief that the cause of an event is the individual's fault, is not likely to change, and affects a variety of situations in the person's life.

Consistent with learned helplessness theories, research has shown that the more people use these attributions, the more they exhibit negative psychological (e.g., Amirkhan, 1998; Bruder-Mattson \& Hovanitz, 1990; Peterson \& Seligman, 1984) and physical symptoms (e.g., Peterson \& Seligman, 1987; Peterson, Seligman \& Vaillant, 1988). However, the goal of the present studies was to show that in an intergroup context of discrimination, global attributions in particular may promote more positive, instrumental behaviors.

\section{Attributions in an Intergroup Context}

Learned helplessness theories have, for the most part been applied in an intrapersonal context, whereby attributions are being made about an event that is happening to that individual alone (e.g., getting sick or being in an accident).

However, intrapersonal events are not the only events about which people make causal attributions. "Why did this happen?" is also a question asked in an intergroup context, namely when a disadvantaged group member experiences discrimination. A woman who has noticed she is being paid less than her male colleagues, of course experiences this event on an individual level. Indeed, defining discrimination as an intrapersonal experience is often a first response by the victim. According to the five stage model of intergroup relations (Taylor \& McKirnan, 1984), a disadvantaged group member may recognize the group's lower status (i.e., recognizing that gender discrimination exists), but given prevalent social ideologies, has been socialized to make internal attributions for his/her own disadvantaged status (e.g., "I'm not good enough to overcome barriers"). Yet, the experience of gender discrimination is, by definition, an event also affecting a collection of individuals. In trying to discern why she is receiving less pay, a woman is also making an attribution for an event that happens to other women. Thus, unlike in an intrapersonal context, the recognition of gender discrimination does not necessarily involve a focus on the individual alone. Instead, there can also be an awareness that others in her group are having a similar experience. As such, intergroup attributions may have different consequences than have traditionally been found in an 
intrapersonal context. In particular, the question that arises is whether internal, stable and global attributions for why discrimination occurs will promote negative consequences, but on a social level. In other words, will internal, stable and global attributions for discrimination promote a social helplessness (accepting unfair treatment) whereas external, unstable and specific attributions promote instrumental social behaviors such as collective action (actions designed to enhance the status of the group)?

\section{External, Unstable Attributions}

Several psychological and sociological theories of intergroup behavior address how causal attributions are related to responses to discrimination. In particular, these literatures agree that making external and unstable attributions for discrimination should be motivational. For example, consistent with learned helplessness theories (e.g., Abramson et al., 1978) both psychology-based intergroup theories such as social identity (Tajfel \& Turner, 1979) and the five stage model (Taylor \& McKirnan, 1984) as well as sociology-based group consciousness theories (e.g., Bartky, 1977; Bowles \& Duelli Klein, 1982; Kimmel, 1989) agree that collective actions to change the system will most likely occur once group members view their social status as due to barriers placed in their way by the social system (external attribution), and when members believe the system can be changed (unstable attribution). Research has shown that external attributions have positive psychological consequences (Crocker \& Major, 1989; Dion \& Earn, 1975; Major \& Schmader, 1998; Ullman, 1996). There is also some research showing that external (Cochran, Frazier \& Olson, 1997; Foster, Matheson \& Poole, 1994) and unstable attributions (Bourhis, 1994; Ellemers, Wilke \& van Knippenberg, 1993) are associated with increased actions to change a negative intergroup situation. Thus, consistent with learned helplessness theories, external and unstable attributions appear to have positive consequences in an intergroup context.

\section{Global Attributions}

There are less empirical research and more theoretical disagreement about the positive consequences of global attributions and as such, the present research will focus on the potential role of global attributions in taking action against discrimination. Within psychology-based intergroup theories, globality has been 
addressed in the form of the construct, "common fate" (Gurin, Hatchett \& Jackson, 1989; Gurin \& Markus, 1989; Gurin \& Townsend, 1986). Common fate is defined as the belief that the group and the individual have a similar fate or experience; whatever affects the group, affects the individual. For example, a woman perceives common fate when she believes her group's disadvantage will also affect her individual status. Once a woman believes that her decreased status is also a function of group membership, then she is more likely to endorse strategies that enhance group status versus individual status (e.g., Gurin \& Markus, 1989). Empirically, studies have shown that a belief in common fate is associated with endorsement of (Gurin \& Townsend, 1986) and participation in collective actions (Foster, 2000a). Thus, the belief that discrimination is global across individuals (i.e., the experience affects the group and the individual) appears to motivate collective action.

It could be argued that common fate does not comprise the definition of globality as learned helplessness theories have defined it (i.e., the cause of an event is pervasive across situations), and as such this theoretical comparison is invalid. In contrast, sociology-based group consciousness theories define global attributions in the same way as learned helplessness theories, but consider them to be motivational. These theories are historically based in grass roots movements such as consciousness-raising groups that sought to redefine women's attributions for discrimination (e.g., Bartky, 1977). In these groups, women came together to talk about everyday experiences, and in doing so heard about each others' experiences of domestic abuse, harassment from teachers, bosses, on the streets from strangers, pay inequities and limited career opportunities. In hearing about the wide variety of ways in which discrimination affected women, they began to reinterpret what was previously thought to be an isolated incident, into something that was affecting many aspects of their lives. For example, a woman who was being paid less than her male colleagues may have initially reasoned that the cause of such treatment was isolated at work (e.g., "my boss is sexist"). However, after hearing about various inequities that were occurring, she presumably came to view the cause of her treatment as able to affect many aspects of her life (e.g., "its happening at home, work, school...everywhere!").

Further, women began to realize that if the experience of the group 
(discrimination) could affect so many aspects of life, then ultimately, they as individual women would not be immune from the effects of discrimination. Global attributions were therefore presumed to make the experience of the group more personally relevant. In other words, global attributions enhanced one's sense of common fate with the group. In turn, it was reasoned that if what happens to the group is personally relevant, then behaviors aimed at enhancing group status would become more relevant to enhancing one's own status. Thus, unlike learned helplessness theories, group consciousness theories suggest global attributions for discrimination should be motivational for collective action via an individual woman's sense of common fate with other women. In support of this, research has shown that the more women believed the cause of discrimination to be global versus specific, the greater was their sense of common fate, and in turn participation in collective action (Foster, 2000a). However, that research did not test the mediated model that is suggested by group consciousness theories (e.g., Bowles \& Duelli Klein, 1982). Thus, the first study was designed to test the hypothesis that the relationship between global attributions and collective action should be mediated by common fate. Specifically, it was hypothesized that (1) common fate and global attributions would be positively related, (2) global attributions would be positively related to collective action, and (3) this relationships would disappear or decrease substantially when common fate is considered.

\section{Study 1}

\section{Method}

\section{Participants and Procedure}

Female participants $(\underline{N}=157$, Mean age $=20.2)$ from psychology courses at the University of North Dakota were asked to read and sign a consent form describing their participation in the study. Reported ethnicity of students was 94\% EuropeanAmerican, .4\% African-American, 1.8\% American-Indian and 3.8\% labeled themselves as "other."

Participants completed a 30-minute questionnaire, after which they were given an oral and written debriefing regarding the purpose of the study.

\section{$\underline{\text { Materials }}$}


$\underline{\text { Attributions for discrimination }}$. Participants read 11 scenarios, each depicting a different situation of discrimination (see Appendix A). The topics of the scenarios were piloted to ensure that they were perceived as discriminatory events (Foster, 1996, 2000a).

Instructions accompanying these situations were as follows: "Imagine yourself in each situation. If such a situation happened to you, what do you think would have caused it? While events may have many causes, we want you to think about the major cause. Keeping that cause in mind, please answer the questions that follow." These instructions and questions were derived from the Attribution Style Questionnaire (ASQ; Peterson, Semmel, von Baeyer, Abramson, Metalsky \& Seligman, 1982). Participants indicated on scales ranging from -5 to +5 how much the cause is due to "something about me" to "something about other people/circumstances" (internal/external), how much the cause is "extremely likely to be present" to "not at all likely to be present again" (stable/unstable) and how much the cause influences "just this situation" to "all other areas of my life" (specific/global.) Higher scores reflected more external, unstable and global attributions for discrimination. The eleven internal/external (Cronbach alpha $=.81$ ), stable/unstable $($ Cronbach alpha $=.88)$ and specific/global $($ Cronbach alpha $=.86)$ items were summed and averaged to be used as the mean attribution scores.

$\underline{\text { Common fate }}$. Participants indicated on a scale ranging from disagree totally $(-5)$ to agree totally (5), their response to 16 statements. Two items were those used by Gurin and Townsend (1986): “The women's movement for women's rights has affected me personally," "What happens to women generally in this country happens to me." To expand the measure, fourteen additional items were included (see Appendix B). The topics on which these items were based were also derived from the pilot data that generated issues that were important to women (Foster, 1996). The reverse scored items were recoded such that on all items, high scores reflected high perceived common fate (Cronbach alpha $=.81)$.

Collective action . Wright, Taylor and Moghaddam (1990) define collective action as any action aimed at enhancing group status as opposed to individual status. Thus, collective action may be taken individually, or with a group, as long as its aim is to enhance group status (e.g., Foster \& Matheson, 1999; Lalonde \& Cameron, 1993; Wright, Taylor \& Moghaddam, 1990). Based on a scale from 
Foster \& Matheson (1995), ranging from "never participate/engage in" (0) to "always participate/engage in" (10), participants indicated how often in their everyday lives they participate in 10 behaviors. Private collective actions were defined as actions that enhance women's status, but require little if any public expression of their commitment to women's issues. This subscale included five behaviors: "I go out of my way to collect information on women's issues"; "I make a conscious attempt to use non-sexist language"; "I keep an eye on the view of my governmental representatives regarding women's issues"; "I attend talks on women's issues"; "Whenever I am presented with a petition(s) advocating the women's movement's position on a social issue (e.g., pro-choice, pay equity, affirmative action), I sign it." The mean of the five items was used as the overall private collective action score $($ Cronbach alpha $=.73$ ). Public collective actions were defined as actions that require greater public expression in that they involve expressing one's commitment to women's issues openly to others, who may or may not be in favor of women's issues. As such, these collective actions, even if not performed with a large group, involve greater risk to the individual (e.g., being openly challenged or ridiculed) in order to help the collective (women). This subscale included five behaviors: "I will correct others' use of sexist language"; "I talk about women's issues with family or friends, stressing the need to enhance women's position in society"; "If in a group of strangers (people who I haven't known for long or well), a sexist comment is made, I will make a point of arguing against it"; "I encourage friends to be aware of women's issues"; "I encourage friends to join organizations that deal with women's issues." The mean of the five items was used as the public collective action scale (Cronbach alpha $=.81$ ).

\section{Results}

\section{Descriptive Statistics}

Means showed that, on average, women made external $(\underline{\mathrm{M}}=3.0, \underline{\mathrm{SD}}=1.4$, Range $=6.6)$ stable $(\underline{\mathrm{M}}=-2.2, \underline{\mathrm{SD}}=1.4$, Range $=7.3)$, and global attributions for discrimination $(\underline{\mathrm{M}}=.95, \underline{\mathrm{SD}}=1.8$, Range $=8.6)$. Ratings of common fate showed that women agreed that their group's disadvantaged status affected them personally $(\underline{\mathrm{M}}=1.23, \underline{\mathrm{SD}}=1.41$, Range $=7.1)$. Participants reported participating in little private $(\underline{\mathrm{M}}=3.06, \underline{\mathrm{SD}}=1.80$, Range $=9.40)$ or public collective action $(\underline{\mathrm{M}}=3.45$, $\underline{\mathrm{SD}}=2.26$, Range $=10)$. 


\section{$\underline{\text { Regression Analyses }}$}

Learned helplessness and group consciousness theories agree on the motivational qualities of external and unstable attributions, and as such the present study sought to examine the unique role of global attributions. At the same time however, the literature on learned helplessness theories examines all three sets of attributions, suggesting that one dimension cannot be examined without the others (e.g., Peterson et al., 1982). As a solution, hierarchical regressions were conducted in order to remain consistent with past research, but to also examine the potential unique role of global attributions. Common fate and the two types of collective action were regressed onto the internal/external, stable/unstable dimensions on the first step, the specific/global dimension on the second step, and the 2-way and 3way interactions on the third and fourth steps respectively. Intercorrelations among the predictor variables showed that the more women made external attributions, the more they also made stable attributions for the discrimination scenarios $(\underline{r}=-.34, \underline{p}$ $=.01)$. The more women made stable attributions, the more they made global attributions for the discrimination scenarios $(\underline{\mathrm{r}}=-.48, \mathrm{p}=.01)$. However, internal/external attributions were unrelated to specific/global attributions $(\underline{r}=.12$, $\mathrm{p}=.129)$.

Results of the regressions appear in Table 1. Internal/external attributions were not related to common fate, or to collective action. Stable/unstable attributions were uniquely related to common fate such that the more women made stable attributions for discrimination, the more common fate they perceived. However, stable/unstable attributions were unrelated to both types of collective action.

Finally, over and above the other attribution dimensions, specific/global attributions were related to common fate and collective action such that the more women made global attributions for discrimination, the more common fate they perceived, and the more they participated in private and public collective action. The two-way and three-way interactions were not significant for any of the dependent variables.

\section{$\underline{\text { Mediation Analyses }}$}

A second set of analyses was conducted to assess the group consciousness theories' hypothesis that common fate mediates the relationship between global attributions and collective action (see Table 2). Baron and Kenny (1986) propose 
three steps to test a mediating relationship. First, there must be a significant relationship between the mediator (common fate) and the independent variable (global attributions). As Table 1 shows, common fate and global attributions are positively related. Second, there must be a significant relationship between the independent (global attributions) and the dependent variable (collective action). Again, as Table 1 shows, global attributions explained $11.3 \%$ of the variability in private collective action, and $9.6 \%$ of the variability in public collective action. Finally, according to Baron \& Kenny (1986), mediation exists if the relation between the independent and dependent variable is no longer significant or is substantially reduced when the mediator is entered into the regression equation. Thus, two additional hierarchical regression analyses were conducted, regressing private and public collective action on common fate on the first step, internal/external and stable/unstable on the second step, and specific/global attributions on the final step (see Table 2). Common fate was significantly related to both private and public collective action such that the more common fate women perceived, the more they participated in private and public collective action. The second step (internal/external, stable/unstable attributions) was unrelated to both private, $\underline{\mathrm{F}}(2,154)=.635, \mathrm{p}=.531$ and public collective action, $\underline{\mathrm{F}}(2,153)=1.37$, $\mathrm{p}$ $=.258$. Finally, over and above common fate and the other attribution dimensions, global attributions continued to explain $4.7 \%$ of the variability in private and $5.8 \%$ of the variability in public collective action. Thus, the relationship between global attributions and collective action was only partially mediated by common fate.

\section{Discussion}

The present study examined how attributions for discrimination were related to responses to discrimination. Although learned helplessness theories would suggest that defining discrimination as pervasive should be associated with helplessness behavior, the present study found global attributions to be motivational. For each type of collective action, defining the cause of discrimination to be global rather than specific was associated with greater collective action. Thus, in contrast to learned helplessness theories, global attributions appeared to have a motivational quality in an intergroup context of discrimination. Group consciousness theories suggest this may be because global attributions serve to make discrimination more personally relevant. In support of this, global attributions were related to common 
fate. The relationship between global attributions and collective action however may only in part be explained by common fate. That is, the amount of variance in private and public collective action explained by global attributions decreased when common fate was considered, but did not become non-significant. Therefore, only a partially mediated model was supported, suggesting that there is something else about global attributions other than its association with common fate, that motivates collective action.

It could be argued however that global attributions had a unique association with collective action because of an artifact of the methodology. This study examined attributions by having women read hypothetical scenarios of discrimination that therefore involved little threat. The benefits of understanding how hypothetical situations impact our lives need not be discounted. The illusion of invulnerability (Perloff, 1983) and unrealistic optimism (Weinstein, 1984) literatures show the importance of hypothetical scenarios in our self-protective behaviors.

Nevertheless, the question remains whether global attributions would be as motivational in a situation where discrimination was not hypothetical but rather explicitly personally relevant. It is possible that once women are personally exposed to discrimination, defining that discrimination as pervasive may be more threatening, and as learned helplessness theories would predict, may decrease motivation to act. In contrast, group consciousness theories (e.g., Bowles \& Duelli Klein, 1983) might argue that the potential for an experience of discrimination can be as threatening as an explicit experience of personal discrimination (e.g., many women feel threatened walking after dark due to the potential for stranger rape). Thus, a second study was designed to assess whether an explicit experience of personal discrimination would alter the relationship between global attributions and collective action. It was hypothesized, consistent with group consciousness theories, that global attributions would remain positively related to taking collective action in a personally experienced situation of discrimination.

Study 2

\section{Method}

\section{$\underline{\text { Participants }}$}

Female $(\underline{N}=79)$ introductory psychology students at the University of North 
Dakota were contacted by phone and asked to participate in a study explained to them as an investigation of how to reduce test-taking anxiety. Participants were told they would receive an experimental credit and were eligible for a $\$ 100$ lottery. Past research has shown that women are more likely to believe deceptions about discrimination if men are present in the experiment (Foster, Matheson \& Poole, 1994). Therefore, men were also included in each session for the purpose of enhancing experimental realism, however they were not included in the analyses. The men were nevertheless eligible for the lottery and fully debriefed.

\section{Procedure}

Participants entered the lab in groups of five to 10 , and were first given an overview of what the experiment would entail. The overview was in reality a cover story designed to conceal the purpose of the study. Specifically, participants were told that this was an experiment in a program of studies that investigated test-taking anxiety. To assess how their anxiety might be related to test performance, they would first complete a task that often appears on standardized language placement tests. They would be given a list of 10 stimulus words to use as the basis for writing a paragraph that is creative, logical and succinct and would be given five minutes to complete these paragraphs. After completion of their paragraphs, their scores would be assessed by the experimenter using the criteria that testing agencies had presumably provided. Allegedly, only the highest scoring participants would then be selected to enter what was called the "video group." The other participants would remain behind to participate in an alleged second part of the experiment.

The purpose of these group delineations is to simulate a meritocractic situation. To reflect a meritocractic organizational context, the methodological goal was to establish a group that participants would aspire to be in and inclusion would reflect personal success and high social value. The second group should represent a lack of success and low social value. This differential evaluation of the two groups was achieved by varying the mundaneness of the task and the rewards associated with the work performed. Supposedly, those who performed well would be asked to provide some ideas about how to develop a video for students that might help them overcome the anxiety associated with test-taking. They were told they would do this in a different experimental room, where refreshments would be served and that they would be eligible for a $\$ 100$ lottery. Thus, their skills were valued by the 
experimenters and they could receive a large reward. In contrast, those who did not perform well would continue to complete a series of tests that would assess whether their performance generalizes to other types of skills such as math. Also, they would only be eligible for a $\$ 10$ lottery. Thus, their continuation in the experiment would be tedious, and their skills less valued by the experimenter, and only a small reward could be received. In reality, the task and scoring were bogus, and all participants were eligible for the $\$ 100$ lottery. This paradigm has been extensively piloted and shown to be effective at creating these group delineations (Foster, 1996, 1999; Foster, Matheson \& Poole, 1994; Matheson, Warren \& Foster, 2000; Wright, Taylor \& Moghaddam, 1990).

To make the potential for gender discrimination salient, the female experimenter warned participants,

I should warn you that this task and the way it is scored could be considered to be discriminatory against women. It seems that women don't do well on this task and so it is very rare that women are allowed into the video group, while men almost always get in. We can talk about this after the experiment if you like, but we do have time limitations for this experiment so we should continue.

Participants were then given five minutes to complete their paragraphs, which were then collected and ostensibly scored. After the scoring, they were given access to their scores. False feedback was given such that only women received a failing score while men received a passing score. Those who passed were then asked to follow the experimenter to a different room where they would presumably participate in the video development. At this point it became clear to participants that consistent with the experimenter's warning, only men received the necessary passing score, and therefore left the room with the experimenter. Thus, the effects of discrimination on the basis of gender were now explicit. After the men had left, a research assistant asked the female participants to complete a questionnaire and told the alleged second part of the experiment would follow the questionnaire. This questionnaire was presumably designed to assess their opinions on the use of the task but actually contained the manipulation checks, attributions for, and responses to their treatment. Once they had completed the questionnaire, they were told that this was the end of the experiment. As in past research (e.g., Foster, 1999) followup interviews consistently showed that participants believed the cover story. After interviews, participants were given an oral and written debriefing. This debriefing 
has been carefully constructed to explain several issues. First, participants are told why sometimes in research the real purpose of the study is initially concealed. The real purpose was then revealed, namely to understand responses to discrimination. In describing this purpose it was made clear that to test responses to discrimination, a situation of discrimination had to be created. It was stressed that this situation was in fact created by the experimenter and as such, no discrimination had actually occurred because the test and the test scores were fake. This was repeated several times throughout the rest of the debriefing. Finally, they were told that they were all eligible to win the $\$ 100$ and that one name would be randomly drawn when the experiment was complete.

\section{Materials}

Manipulation checks To assess whether participants recognized the discrimination that was portrayed, they were asked to indicate on a scale ranging from "not at all" (0) to "extremely" (10), "how much does this task discriminate against your gender?" and "how much does the task discriminate against you personally due to your gender?"

Attributions . Attribution questions were again based on the ASQ (Peterson et al., 1982), but reworded to refer to their treatment in the experiment. Participants read an introductory statement that referred to all three attribution questions: "Today in the experiment you were told that you either passed or failed a certain task." Internal/external attributions were then assessed by asking "How much was your passing or failing was due to something about you or something about other circumstances?" Stable/unstable attributions were assessed by asking "In the future, will the reason you either passed or failed the task be present, i.e., will it affect your performance in the future?" Specific/global attributions were assessed by asking, "Does the reason you either passed or failed the task influence just this situation, or does it also influence other areas of your life?". All questions were scored along a -5 to +5 scale so that higher scores reflected external, unstable and global attributions.

Responses to discrimination. Measures of responses to discrimination were adapted from Wright, Taylor \& Moghaddam (1990). Using a scale ranging from "extremely unlikely to participate" (0) to "extremely likely to participate" (10), 
participants indicated the extent to which they would participate in each of five behaviors given the opportunity to respond to their treatment in the present experiment. One item reflected helplessness behavior ("Accept the situation, that is, your assignment to either group, as is"). Two items reflected individual behaviors, that is behavior aimed at enhancing individual status ("Request an individual retest of your score“; "Confront the experimenter and demand an explanation of your particular group assignment." The mean of these two items was used as the overall individual action score, $\underline{\mathrm{r}}=.47, \mathrm{p}=.01)$. Two items reflected collective behaviors, that is, behaviors aimed at enhancing group status ("Ask that the group be retested on their scores"; "Get together with other students to confront the experimenter, demanding an explanation for your group assignment." The mean of these two items was used as the overall collective action score, $\underline{r}=.86, \underline{p}=.01$ ).

\section{Results}

\section{Manipulation Checks}

For the discrimination manipulation to have been successful it was desirable that participants recognize at least a moderate amount of discrimination. This would be consistent with self-report perceptions of discrimination by minority group members (e.g., Foster \& Matheson, 1995; Taylor, Wright, Moghaddam \& Lalonde, 1990). Women recognized that discrimination occurred on a group level ( $\underline{M}=6.92$, $\underline{\mathrm{SD}}=2.84$, Range $=8)$ as well as on a personal level $(\underline{\mathrm{M}}=6.01, \underline{\mathrm{SD}}=3.06$, Range $=$ 10). Thus, the manipulation of gender discrimination appeared to be personally relevant.

\section{Descriptive Statistics}

Women made external $(\underline{\mathrm{M}}=.77, \underline{\mathrm{SD}}=3.3$, Range $=10)$, unstable $(\underline{\mathrm{M}}=2.85, \underline{\mathrm{SD}}$ $=2.60$, Range $=10)$ and specific attributions for discrimination, $(\underline{\mathrm{M}}=-1.15, \underline{\mathrm{SD}}=$ 3.13, Range $=10$ ) attributions for their discrimination. The tendency to endorse acceptance of unfair treatment was moderate, $(\underline{\mathrm{M}}=4.2, \underline{\mathrm{SD}}=3.5$, Range $=10)$, and consistent with Study 1 , the tendency to endorse individual $(\underline{\mathrm{M}}=3.5, \underline{\mathrm{D}}=2.9$, Range $=10)$ and collective action $(\underline{\mathrm{M}}=3.4, \underline{\mathrm{SD}}=3.3$, Range $=10)$ was low.

\section{$\underline{\text { Regression Analysis }}$}

As in Study 1, three hierarchical regression analyses were conducted to examine 
how attributions for discrimination were related to responses to discrimination.

Each type of response (acceptance, individual and collective behavior) was regressed onto the internal/external and stable/unstable dimensions on the first step, the specific/global dimension on the second step, and the two-way and three-way interactions on the third and fourth steps respectively. Intercorrelations among the predictor variables showed that the more women made external attributions, the more they also made stable attributions for the discrimination scenarios $(\underline{r}=-.33, \underline{p}$ $=.01$ ). The more women made stable attributions, the more they made global attributions for the discrimination scenarios $(\underline{\mathrm{r}}=-.25, \mathrm{p}=.01)$. However, as in Study 1 , internal/external attributions were unrelated to specific/global attributions ( $\underline{\mathrm{r}}=.12, \mathrm{p}=.135)$.

Results for the regression analyses appear in Table 3. Internal/external attributions were related to acceptance of unfair treatment, individual and collective action such that the more women blamed external factors, the less likely they were to endorse acceptance and the more likely they were to endorse both individual and collective action against their unfair treatment. Stable/unstable attributions were unrelated to all three dependent variables. Specific/global attributions were related to acceptance, individual and collective action such that the more women made external attributions the less likely they were to endorse acceptance, and more likely to endorse individual and collective action.

The two-way and three-way interactions were not significant.

\section{Discussion}

As expected, global attributions still appeared to motivate women's tendency to endorse collective action against unfair treatment. In addition to being motivational on a collective level, Study 2 showed that global attributions were also associated with greater individual actions, namely actions aimed at enhancing one's individual rather than group status. This suggests that global attributions for discrimination context also have positive implications for psychological well-being. Because past research has shown that the experience of discrimination is also associated with depression and anxiety (Foster, 2000-b; Landrine, Klonoff, Gibbs, Manning \& Lund, 1995), taking individual-level actions to resolve the discrimination may help to alleviate negative affect associated with the experience of discrimination. In an intergroup context then, global attributions seem important for both psychological 
and social benefits.

An unexpected finding in Study 2 was that there appeared to be a slight change in the pattern of attributions from Study 1: while women in both hypothetical and experienced situations of discrimination were unlikely to blame themselves, women in Study 2 believed the cause of their discrimination was unstable and specific. This change in attributions may be because the unfair treatment experienced by participants was a function of them participating in a psychology experiment. The laboratory situation, by definition will not exist after their participation in the experiment is completed, and is an isolated experience. Thus, despite believing the task was discriminatory, participants appeared to believe that they would not encounter such discrimination outside the confines of the laboratory.

Alternatively, it may be that women in Study 2 reported different attributions due to the threatening nature of a personal versus hypothetical experience of discrimination. For example, in the case of rape, women who use behavioral self-blame attribute the rape to something they can change and something that is isolated (e.g., wearing a short skirt). It has been suggested that this is a strategy to gain control over an uncontrollable situation; if they can change the situation, they will not be hurt again (e.g., Janoff-Bulman, 1982). Similarly, a personally experienced situation of discrimination experienced in real life may be so threatening that women need to make unstable and specific attributions for selfprotective means, namely to feel some control over possible future discrimination. Future research may benefit from examining a change in attribution patterns by using a repeated-measures design to discern whether changes are indeed due to changes in the situation rather than a change of sample.

\section{General Discussion}

Traditional research suggests that global attributions decrease instrumental behaviors to resolve negative situations. In contrast, these studies suggest that in an intergroup context, global attributions are related to less acceptance of unfair treatment and increased action against discrimination. One explanation put forth by group consciousness theories (e.g., Bowles \& Duelli Klein, 1983) is that defining the cause of discrimination to be pervasive makes discrimination personally relevant. That is, if women view the cause of discrimination to be apparent at 
home, work and school of other women's lives, they may reason that "it's going to affect me, too.” Even beyond making discrimination personally relevant, global attributions predicted collective action, both when common fate was statistically controlled for, and when discrimination was made explicitly personally relevant. Thus, global attributions also appear to play a unique role in taking action against discrimination. It may be that once discrimination is considered pervasive, people become aware that pervasive actions must be taken, namely actions that can affect the system (collective action). In addition, it may be something about the intergroup context that motivates action on both an individual and collective level. In particular, given the event is happening to a group of people, individuals may feel a sense of social support by knowing "it's not just me." As such, the traditionally overwhelming nature of global attributions may be reduced, making any action against discrimination easier.

It is arguable however the extent to which collective action was in fact easier. In particular, despite recognizing that discrimination exists, collective action was low in both studies, suggesting that a recognition of discrimination may be a necessary but not sufficient cause of collective action. On the one hand, this is consistent with past research (Foster \& Matheson, 1995, 1999; Matheson, Echenberg, Taylor, Rivers \& Chow, 1994; Taylor, Moghaddam, Gamble \& Zellerer, 1987; Taylor et al., 1990), and as such may simply reflect society's more apathetic nature compared to the social activism in the 1960s/1970s. Alternatively, low levels of collective action may be a function of the collective action measures used. Although Study 1 did assess participation in action, study two only assessed endorsement of action. It may be useful to examine more realistic measures of action in response to an experienced situation of discrimination (e.g., asking women to sign a petition against the use of sexist measures in the department's research practices). In addition, the operational definition of public collective action may be expanded to included high-level public actions such as participating in protest marches. Finally, low levels of collective action may have been a function of the student population.

While the incidence of discrimination within the student population is substantial (e.g., reports show that between $9 \%$ and $38 \%$ of college women are harassed (Dziech \& Weiner, 1990; Martin, 1995) and therefore responses to discrimination by university women are important to understand, examining women in social movements may provide additional information regarding the role of global 
attributions in motivating collective action.

Despite these limitations, the present study suggests new theoretical and practical implications. Theoretically, these studies suggest that learned helplessness theories may need to be expanded in order to be predictive within an intergroup context. Perhaps one reason learned helplessness theories have not been applied in an intergroup context is that they assume that attributions fall together into two distinct explanatory styles, namely the depressive attributional style (internal, stable and global) and its healthier counterpart (external, unstable and specific attributions) (Abramson, Seligman \& Teasdale, 1978; Seligman et al., 1979). However, research on attributions for discrimination suggests that external attributions are not always associated with unstable attributions and specific attributions. Women coping with rape for instance may use "characterological" self-blame, which involves internal, stable and global attributions ("It was my fault, it always will be and it will affect everything I do"). However, rape victims also use "behavioral" self blame, which involves attributing the rape to something about one's behavior (e.g., Frazier, 1990). Therefore, while internal attributions are made ("I wore the wrong outfit"), the behavior is unstable and specific ("but I won't wear it again, it was only that one situation"). In this case, attributions for discrimination do not necessarily fall together in the same way that has been found in intrapersonal contexts. Thus, expecting one explanatory style as they have been traditionally examined in an intrapersonal context may not necessarily be appropriate, and, as was done in the present studies, examining the unique contributions of each attribution may be helpful.

On a practical level, the finding that global attributions provide individual and social benefits, suggests that institutional policies for publicizing information about discrimination may need to be reconsidered. Traditionally, institutions such as universities or corporations, and even the police often withhold information about the incidence of discrimination from the public. On the one hand this is beneficial in that making any incident of discrimination appear isolated rather than widespread may help to reduce the potential for "public panic." For examples, universities may not make rape and sexual harassment incidence statistics easily available to their students. Many students may therefore believe that rape and harassment is isolated to places off- campus. In doing so, the institution may believe it has made it easier 
for potential victims of discrimination to function on a daily basis without feelings of fear or helplessness. However, as the present study suggests, by encouraging a sense that discrimination is isolated, potential victims of discrimination may believe they are invulnerable to effects of discrimination, which may lead to fewer selfprotective behaviors (e.g., Weinstein, 1984, 1989). Thus, by implying the discrimination is isolated, institutions may be encouraging the very behavior (helplessness) they seek to prevent. Instead, if institutions disclose their information regarding the risk of discrimination, potential victims may recognize they too are vulnerable, which in turn will enhance their ability to help both themselves and their group, to challenge discrimination.

\section{References}

Abramson, L. Y., Metalsky, G. I., \& Alloy, L. B. (1989). Hopelessness depression: A theory-based subtype of depression. Psychological Review, 96 , 358372.

Abramson, L. Y., Seligman, M. E. P., \& Teasdale, J. (1978). Learned helplessness in humans: Critique and reformulation. Journal of Abnormal Psychology, $, 87,49-74$.

Amirkhan, J. H. (1998). Attributions as predictors of coping and distress. Personality and Social Psychology_Bulletin , 24, 1006-1018.

Baron, R. M., \& Kenny, D. A. (1986). The moderator-mediator variable distinction in social psychological research: Conceptual, strategic and statistical considerations. Journal of Personality and Social Psychology , $\underline{51}, 1173-1182$.

Bartky, S. L. (1977) Toward a phenomenology of feminist consciousness. In M. Vetterling-Braggin, F. Elliston, \& J. English (Eds.), Feminism and philosophy (pp. 22-37). Totawa, NJ: Littlefield.

Birt, C. M. \& Dion, K. L. (1987). Relative deprivation theory and responses to discrimination in a gay male and lesbian sample. British Journal of Social Psychology, 26, 139-145.

Bourhis, R. Y. (1994). Power, gender and intergroup discrimination: Some minimal group experiments. In M. P. Zanna \& J. M. Olson (Eds.), The psychology of prejudice: The Ontario symposium (Vol. 7, pp. 171-208). Hillsdale, NJ: 
Lawrence Erlbaum Associates.

Bowles, G. \& Duelli Klein, R. (1983). Theories of women's studies . London: Routledge.

Bruder-Mattson, S. F., \& Hovanitz, C. A. (1990). Coping and attributional styles as predictors of depression. Journal of Clinical Psychology, $\underline{46}, 557-565$.

Cochran, C. C., Frazier, P. A., \& Olson, A. W. (1997). Predictors of responses to unwanted sexual attention. Psychology of Women Quarterly, 21 (2), 207-226.

Crocker, J., \& Major, B. (1989). Social stigma and self-esteem: The selfprotective properties of stigma. Psychological Review , $\underline{96}, 608-630$.

Dion, K. L., \& Earn, B. M. (1975). The phenomenology of being a target of prejudice. Journal of Personality and Social Psychology,_32, 944-950.

Dziech, B. W., \& Weiner, L. (1984). The lecherous professor: Sexual harassment on campus (2 nd ed.). Urbana: University of Illinois Press.

Ellemers, N., Wilke, H., \& van Knippenberg, A. (1993). Effects of the legitimacy of low group or individual status on individual and collective status-enhancement strategies. Journal of Personality and Social Psychology , 64 (5), 766-778.

Foster, M. D. (2000-a). Utilization of global attributions in recognizing and responding to gender discrimination among college women. Current Psychology, $\underline{19}, 57-69$.

Foster, M. D. (2000-b). Positive and negative responses to personal discrimination: Does coping make a difference? Journal of Social Psychology, 140 , 93-106.

Foster, M. D. (1999). Acting out against discrimination: The effects of different social identities. Sex Roles, 40,167-186.

Foster, M. D. (1996). The socio-cognitive factors in reducing the personal/group discrimination discrepancy. Unpublished doctoral dissertation. Carleton University, Ottawa, Canada.

Foster, M. D., \& Matheson, K. (1995). Double relative deprivation: Combining the personal and political. Personality and Social Psychology_Bulletin, 21, 1167- 
1177.

Foster, M. D., \& Matheson, K. (1998). Perceiving and feeling personal discrimination: Motivation or inhibition for collective action? Group Processes and Intergroup Relations , 1 (2), 165-174.

Foster, M. D. \& Matheson, K. (1999). Perceiving and responding to the personal/group discrimination discrepancy Personality and Social Psychology Bulletin, $\underline{25}, 1319-1329$.

Foster, M. D., Matheson, K. \& Poole, M. (1994). Responding to Sexual Discrimination: The effects of societal versus self-blame. Journal of Social Psychology, $, \underline{134}, 743-754$.

Frazier, P. A. (1990). Victim attributions and post-rape trauma. Journal of

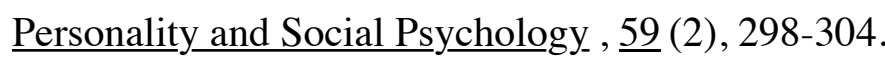

Gurin, P., Hatchett, S., \& Jackson, J. S. (1989). Hope and independence: Blacks' response to electoral and party_politics . New York: Russell Sage Foundation.

Gurin, P., \& Markus, H. (1989). Cognitive consequences of gender identity. In S. Skevington \& D. Baker (Eds.), The social identity of women (pp. 152-172). Newbury Park, CA: Sage.

Gurin, P., \& Townsend, A. (1986). Properties of gender identity and their implications for gender consciousness. British Journal of Social Psychology , 25, 139-148.

Janoff-Bulman, R. (1982). Esteem and control bases of blame: "Adaptive" strategies for victims versus observers, Journal of Personality, 50, 180-192.

Kimmel, E. B. (1989). The experience of feminism. Psychology of Women Quarterly, $13,168-186$.

Lalonde, R. N., \& Cameron, J. E. (1993). Behavioral responses to discrimination: The focus on action. In M. P. Zanna \& J. M. Olson (Eds.), The psychology of prejudice: The Ontario Symposium (Vol. 7, pp. 257-288). Hillsdale, NJ: Erlbaum.

Landrine, H., Klonoff, E. A., Gibbs, J., Manning, V., \& Lund, M. (1995).

Physical and psychiatric correlates of gender discrimination: An application of the 
schedule of sexist events. Psychology_of Women Quarterly,_19 (4), 473-492.

Major, B. \& Schmader, T. (1998). Coping with stigma through psychological disengagement. In J. K. Swim \& Stangor, C. (Eds.), Prejudice: The target's perspectiv e (pp. 219-241). San Diego, CA: Academic Press.

Martin, S. E., (1995). Sexual harassment: The link joining gender stratification, sexuality and women's economic status. In J. Freeman (Ed.), Women: A feminist perspective (5 th ed., pp-22-46). Mountain View, CA: Mayfield.

Matheson, K., Echenberg, A., Taylor, D. M., Rivers, D., \& Chow, I. (1994). Reactions to affirmative action: Seeking the bases for resistance. Journal of Applied Social Psychology , 24, 2075-2096.

Matheson, K., Warren, K. \& Foster, M. D. \& Painter, C. (2000). Reactions to affirmative action: Seeking the bases for resistance. Journal of Applied Social Psychology, 30, 1013-1038.

Perloff, L. S. (1983). Perceptions of vulnerability to victimization. Journal of $\underline{\text { Social Issues }}, \underline{39}, 41-61$.

Peterson, C. \& Seligman, M.E. P. (1984). Causal explanations as a risk factor for depression: Theory and evidence. Psychological Review , 91 , 347-374.

Peterson, C. \& Seligman, M. E. P. (1987). Explanatory style and illness. Journal of Personality, , $\underline{55}$, 237-265.

Peterson, C. , Seligman, M. E. P., \& Vaillant, G. E. (1988). Pessimistic explanatory style is a risk factor for physical illness: A thirty-five year longitudinal study. Journal of Personality and Social Psychology , $\underline{55}$, 23-27.

Peterson, C., Semmel, A., von Baeyer, C., Abramson, L. Y., Metalsky, G.I., \& Seligman, M. E. P. (1982). The attributional style questionnaire. Cognitive Therapy and Research, 6 , 287-299.

Seligman, M. E. P. (1975). Helplessness: On depression, development and death. San Francisco: Freeman.

Tajfel, H., \& Turner, J. C. (1979). An integrative theory of intergroup conflict. In W. G. Austin \& S. Worchel (Eds.), The social psychology of intergroup relations . 
Monterey, CA: Brooks/Cole.

Taylor, D. M., \& McKirnan, D. J. (1984). A five-stage model of intergroup relations. British Journal of Social Psychology , 23 , 291-300.

Taylor, D. M., Moghaddam, F. M., Gamble, I., \& Zellerer, E. (1987).

Disadvantaged group responses to perceived inequality: From passive acceptance to collective action. Journal of Social Psychology, 127, 259-272.

Taylor, D. M., Wright, S. C., Moghaddam, F. M. \& Lalonde, R. N. (1990). The personal/group discrimination discrepancy: Perceiving my group, but not myself, to be a target for discrimination. Personality and Social Psychology Bulletin , $\underline{16}$, 254-263.

Ullman, S. E. (1996). Social reactions, coping strategies, and self-blame attributions in adjustment to sexual assault. Psychology of Women Quarterly, 20 (4), 505-526.

Weinstein, N. D. (1984). Why won't it happen to me: Perceptions of risk factors and susceptibility. Health Psychology,$\underline{3}$, 806-820.

Wright, S. C., Taylor, D. M., \& Moghaddam, F. M. (1990). Responding to membership in a disadvantaged group: From acceptance to collective protest. Journal of Personality and Social Psychology , $\underline{58}$, 994-1003.

Appendix A

Scenario 1:

Imagine your male employer tells you that your productivity has been low and that it is clear you are not attracting new clients to the firm. He says to you that he is willing to help you out if you will see him on a social basis. While you resist, he reminds you that if you were performing as you should, there would be no need for this special attention he can give you.

Scenario 2:

Imagine you've been working at your job for over a year. A new guy is hired and you are asked to "show him the ropes". You notice that he and your boss, John get along very well--John praises the new guy's performance, and the two of them are always talking sports, things that you simply are not interested in. After a couple months you find out he is getting all the best shifts.

Scenario 3: 
You entered graduate school, but unlike most students, your advisor was unable to secure your funding. She says that she has tried hard, but has been unsuccessful and suggests you talk to the Chair of the department yourself. He tells you that if you came to work for him (he would be your new advisor) he could get you funding.

Scenario 4:

It's time for college applications and you go to your guidance counselor with an ambition to major in the sciences. However, he suggests that you should perhaps consider a major that better suits the personalities of women, namely early childhood education. He explains that women are naturally nurturing and therefore, succeed in childhood education programs more so than science programs.

Scenario 5:

As a part of a demonstration in one of your classes, the whole class is asked to complete a short task assessing your cognitive ability. The professor warns the class that the women should try extra hard because this particular measure has been known to yield low scores for women, while men end up always performing well. The professor grades the tasks after everyone has completed it and says, "The men performed well, the women did not".

Scenario 6:

Suppose you are out jogging, and you pass a large group of guys. They start yelling and whistling at you: "Hey baby--looking good--why don't bring that over here baby"

Scenario 7:

Imagine you just completed graduate school--6 long years of studying and researching! You have finally earned the title "Dr." and you are very proud of yourself. During the term however your students refer to you as "Miss", and refer to your male colleagues as "Dr.

Scenario 8:

You bring your car in to the garage to be fixed. You're not very confident about your car knowledge, but you've just completed a beginner's course on how to better understand your car. You tell the mechanic you believe the problem is a loose fan belt, but you can't be sure. $\mathrm{He}$ responds “Don't worry honey, we know more about this stuff--we'll do the diagnosing".

Scenario 9:

Suppose again you are out jogging, and you pass a large group of guys. They start yelling and whistling at you: "Hey baby--looking good--why don't bring that over here baby". But you ignore them, and cross to the other side of the street. Seeing your lack of interest they yell "Bitch!" 


\section{Scenario 10:}

You just got a job at a very popular new restaurant, which is great because you could really use the money that good tips can bring in. A friend says to you, "You know, you have great legs-if you show them off, you could get better tips."

\section{Scenario 11}

Imagine you are asked out by a guy you've been interested in for a while. You are very excited and spent a lot of time picking out the right clothes to make sure he was as attracted to you as you are to him. He takes you to dinner and a movie, and you sense that everything “clicks"--you feel like you've known him forever, and all you can think about is that first kiss.

After the date, you invite him to your room for some coffee and you are both cuddled quite close on the couch waiting for the coffee to brew. He kisses you and its as wonderful as you imagined--but he doesn't stop. He climbs on top of you and you are saying "STOP" but he doesn't listen. He ends up penetrating you. When he has finished, he leaves saying, "You should be careful not to tease so much".

\section{Appendix B}

1. Hearing about women being raped increases my concern for my personal safety.

2. Even if women have to work harder than men to be successful, that will not affect how hard I have to work.

3. Sexist jokes that are hurtful to women often hurt me personally.

4. In general, women's status has nothing to do with my personal status.

5. Obstacles that women face at work will ultimately affect me in my career.

6. Realizing the kinds of discrimination women face has led me to believe that I too could face discrimination.

7. While girls are generally treated worse than boys by teachers (especially science teachers), this has little to do with how my teachers treated me.

8. Unfair treatment of women in general will affect me at some point in my life.

9. I share a common bond with women.

10. Given that women in general are expected to work and perform most household responsibilities, this will likely be expected of me too.

11. While women get paid $30 \%$ less than men on average, this won't impact on how much my employers will pay me.

12. Given how common sexual harassment is for women, it is likely to affect me at some point. 
13. The media's ideal woman as "thin, beautiful and sexy" has affected my own image of myself (either to achieve, or ignore it).

14. Given that women are often limited to lower level jobs (being assistants vs. executives), this will likely limit career options open to me.

Table 1

Summary of Hierarchical Regressions for Study 1

Dependent Predictor

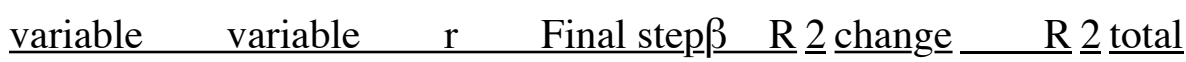

Common Fate

Step 1: Internal/External .13 - -.01

Stable/Unstable $-.37 * * \quad-.38 * * \quad .140 * *$

Step 2: Specific/Global $.40 * * \quad .29 * * \quad .066^{* *} \quad .206 * *$

Private collective action

Step 1: Internal/External .06 $\quad .07$

Stable/Unstable $-.05 \quad .05 \quad .005$

Step 2: Specific/Global $.32 * * \quad .39 * * \quad .113 * * \quad .118 * *$

Public collective action

Step 1: Internal/External .18 $\quad .16$

Stable/Unstable -.14 $\quad .08 \quad .039$

Step 2: Specific/Global $.33^{* *} \quad .36^{* *} \quad .096^{* *} \quad .135^{* *}$

$\underline{\text { Note }}$ : Higher scores reflect higher external, unstable and global attributions as well

as common fate and participation in all actions.

$* * \mathrm{p}<.01, * \mathrm{p}<.05$

Table 2

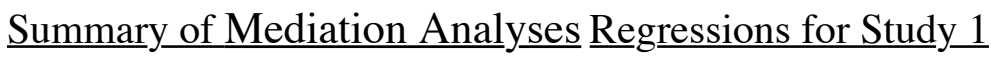

Dependent Predictor

variable variable $\quad r \quad$ Final step $\underline{\beta} \quad \mathrm{R} \underline{2} \underline{\text { change }} \quad \mathrm{R} \underline{2} \underline{\text { total }}$

Private collective action

Step 1: Common fate $.41 * * \quad .37 * * \quad .160 * *$

Step 2: Internal/External .04 $\quad .05$

Stable/Unstable $\quad .08 \quad .20 \quad .007$

Step 3: Specific/Global .34** .28** .047** $\quad .214 * *$

Public collective action

Step 1: Common fate $.35 * * \quad .43 * * \quad .180 * *$ 
Step 2: Internal/External .13 .17

Stable/Unstable $.17 \quad .14 \quad .014$

Step 3: Specific/Global $.26^{* *} \quad .36^{* *} \quad .058^{* *} \quad .252^{* *}$

$\underline{\text { Note }}$ : Higher scores reflect higher external, unstable and global attributions as well

as common fate and participation in all actions.

$* * \mathrm{p}<.01, * \mathrm{p}<.05$

Table 3

Summary of Regressions for Study 2

Dependent Predictor

variable variable $\quad \mathrm{r} \quad$ Final step $\underline{\beta} \underline{\mathrm{R}} \underline{\underline{2}} \underline{\text { change }} \underline{\mathrm{R}} \underline{\underline{2}} \underline{\text { total }}$

Accept treatment

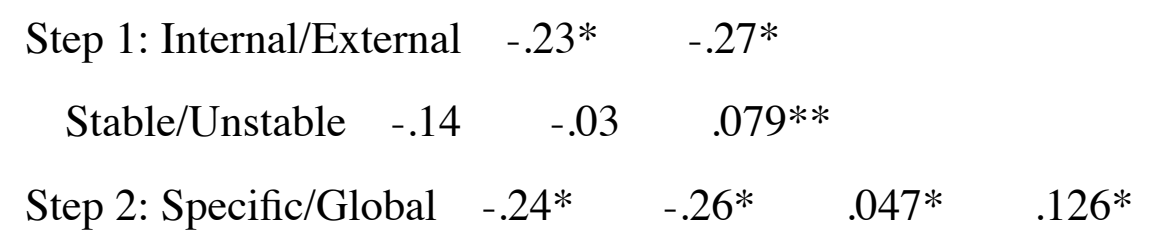

Individual status

Step 1: Internal/External $\quad .38^{* *} \quad .42^{* *}$

Stable/Unstable $\quad .16 \quad .01 \quad .183^{* *}$

Step 2: Specific/Global $\quad .31 * * \quad .35 * * \quad .084 * * \quad .267 * *$

Collective status

$\begin{array}{ccclll}\text { Step 1: Internal/External } & .36^{* *} & .41^{* *} & \\ \text { Stable/Unstable } & .12 & -.01 & .159^{* *} & & \\ \text { Step 2: Specific/Global } & .27 * * & .33^{* *} & .076^{*} & .235^{* *}\end{array}$

$\underline{\text { Note }}$ : Higher scores reflect higher external, unstable and global attributions as well

as participation in all actions.

$* * \mathrm{p}<.01, * \mathrm{p}<.05$ 